\title{
Effect of antimicrobial factors in human milk on rhinoviruses and milk-borne cytomegalovirus in vitro
}

\author{
N. M. CLARKE and J. T. MAY
}

Department of Microbiology, LaTrobe University, Bundoora, Victoria, 3083 Australia

\begin{abstract}
Various antimicrobial factors present in human milk were tested for in-vitro antiviral activity against three rhinoviruses (two clinical isolates and rhinovirus 2) and an isolate of cytomegalovirus (CMV) from human milk. These factors included the gangliosides GM1, 2 and 3, sialyl-lactose, chondroitin sulphates $A, B$ and $C$, prostaglandins $E 2$ and F2 $\alpha$, monolaurin, vitamin $A$ and the protein lactoferrin. All were tested for their ability to inhibit growth of the viruses in cell culture. Human milk was also tested for antiviral activity against these viruses. Only vitamin $A$, monolaurin and lactoferrin inhibited the growth of CMV, whereas both prostaglandins enhanced the growth of this virus at least four-fold. CMV infects infants from milk but, nevertheless, the milk-borne CMV isolate showed no special resistance to any of the antiviral factors tested. None of the compounds inhibited or enhanced the growth of the rhinoviruses. However, human milk decreased the growth of some of the rhinoviruses and specific secretory immunoglobulin A (sIgA) neutralised the virus.
\end{abstract}

\section{Introduction}

Breast-feeding is known to protect against respiratory and gastrointestinal infections as well as otitis media (middle ear infections) in infants [1-3]. Human milk contains various factors with known antiviral or antibacterial activity in vitro $[1,4]$. Recently, respiratory syncytial virus (RSV) and, more particularly, rhinoviruses have been implicated in predisposing infants to and causing otitis media [5, 6]. Rhinoviruses also cause middle ear problems in adults [7]. Unlike RSV, with which various factors present in human milk are known to inhibit growth in vitro $[1,4,8]$, no human milk components have been tested on rhinovirus growth. Bovine milk was reported to have a negligible effect on rhinovirus growth in vitro [9].

Cytomegalovirus (CMV) is a herpesvirus which infects infants and is commonly found in milk from $>40 \%$ of CMV-seropositive mothers [1]. About two-thirds of infants fed CMV-containing milk become infected but never develop any symptomatic disease from this source [1]. However, one report has indicated that CMV symptoms can appear in some extremely low-

Received 19 Oct. 1999; revised version accepted 10 Jan. 2000.

Corresponding author: Dr J. T. May (e-mail: micjm@luff. latrobe.edu.au). birth-weight infants fed with their mother's CMVcontaining milk [10]. While the enveloped virus CMV is commonly found in human milk, many factors are present in milk which can inactivate CMV, particularly during storage of the virus [11-13]. The present study used an isolate of a milk-borne $\mathrm{CMV}$ that survived storage for 2 days at $4{ }^{\circ} \mathrm{C}$ in human milk (a gB3 subtype) and attempted to investigate why this isolate was resistant to inactivation by these milk compounds. Previous studies [4] used a clinical isolate of CMV (a gB1 subtype). Of the four glycoprotein B subtypes of CMV, gB1 and $\mathrm{gB} 3$ are the most common types infecting children [14].

A wide variety of factors in human milk has been found to be active against the growth of enveloped viruses in vitro, but only immunoglobulin has been considered important in stopping the growth of nonenveloped viruses. This occurs by neutralisation of the viruses with virus-specific secretory immunoglobulin A (sIgA) [15]. However, lactoferrin of bovine origin can inhibit growth of simian rotavirus SA11 [16], as can ganglioside GM1 [4]. Either bovine or human milk lactoferrin can interfere with growth of poliovirus type 1 [17]. Vitamin A (a lipid-containing compound) inhibited growth of simian virus 40 [18]. These viruses are all non-enveloped. Lactoferrin, an antibacterial agent, is also known to have strong antiviral activity against various enveloped viruses such as CMV, RSV, 
human immunodeficiency virus (HIV), herpes simplex virus (HSV) [4] and hepatitis C virus [19]. Chondroitin sulphates $\mathrm{A}$ or $\mathrm{C}$ inhibit HIV binding to its host cell CD4 receptor [4]. Vitamin A also had antiviral activity against HSV [18] and, recently, vitamin A deficiency in women has been linked to increased shedding of HIV in milk [20]. Vitamin A is released from its ester forms (mainly palmitate) by milk lipase activity. Human milk contains free fatty acids and monoglycerides, which are also generated by milk lipase activity [11], and these have potent antiviral activity against enveloped viruses, including HIV [21, 22]. One lipid, monolaurin, also has strong antibacterial activity [23]. Prostaglandins PGE2 and PGF $2 \alpha$ inhibit the growth of parainfluenza 3, a respiratory virus of infants [8]. These compounds were tested for their ability to inhibit both CMV and rhinovirus growth in vitro.

\section{Materials and methods}

The purified compounds used were all purchased from Sigma. Lactoferrin and sialyl-lactose were from human milk. They were dissolved at a concentration of $5 \mathrm{mg} / \mathrm{ml}$ in phosphate-buffered saline (PBS). Monolaurin and vitamin A were dissolved at $20 \mathrm{mg} / \mathrm{ml}$ and the prostaglandins at $1 \mathrm{mg} / \mathrm{ml}$ in absolute ethanol. All were used fresh or stored at $-20^{\circ} \mathrm{C}$ for a week.

Three rhinoviruses were used, a prototype rhinovirus 2 strain and two untyped clinical isolates. The clinical isolates were from infants suffering from bronchiolitis, one from a 1-month-old child (C19843) and the other from an 11-month-old child (C19900). The rhinoviruses were grown in $\mathrm{HeLa}-\mathrm{T}$ cells at $33^{\circ} \mathrm{C}$ with a solid agarose $1 \%$ overlay medium, as described previously $[11,24]$, for 5 days, yielding plaques of 3-4 $\mathrm{mm}$.

A CMV isolate from pre-term milk and a clinical CMV isolate (C37), used previously [4], were grown in human embryo lung cells (HEL) at $37^{\circ} \mathrm{C}$. Plaques were counted after growth for 7 days on HEL cells in medium without agarose, as described previously $[4,11]$.

Various concentrations of compounds were tested for their inhibitory action on 80-100 plaque forming units (in $0.1 \mathrm{ml}$ ) of virus in duplicate and repeated in at least triplicate experiments. Only the maximum concentrations used are shown in Table 1. Controls of viruses treated in a similar manner, without the added compounds, were included in all experiments. Lactoferrin, gangliosides, chondroitin sulphates and sialyllactose were absorbed on to cells $30 \mathrm{~min}$ before the absorption of the viruses. The viruses were then allowed to absorb on to the cells for $1 \mathrm{~h}$ before addition of the overlay medium. Prostaglandins were incorporated into the overlay medium after the absorption of the virus for $1 \mathrm{~h}$ [8]. Monolaurin, vitamin $\mathrm{A}$ and human milk $(50 \% \mathrm{v} / \mathrm{v})$ were added to a virus solution and pre-treated for $1 \mathrm{~h}$ at $37^{\circ} \mathrm{C}$ before absorption on to the cells and the application of

Table 1. Effects of different concentrations of various compounds from milk on growth of rhinoviruses and CMV

\begin{tabular}{|c|c|c|c|c|}
\hline \multirow[b]{3}{*}{ Compound $(\mu \mathrm{g} / \mathrm{ml})$} & \multicolumn{4}{|c|}{ Percentage decrease (or increase + ) in virus titre of } \\
\hline & \multicolumn{3}{|c|}{ Rhinoviruses } & \multirow[b]{2}{*}{ Milk-borne CMV } \\
\hline & 2 & C19843 & C19900 & \\
\hline \multicolumn{5}{|c|}{ Pre-treatment of cells for $30 \mathrm{~min}$} \\
\hline Lactoferrin (1000) & 10 & 0 & 0 & 99 \\
\hline \multicolumn{5}{|l|}{ Ganglioside (500) } \\
\hline GM1 & 10 & 0 & 0 & 10 \\
\hline GM2 & 0 & 0 & 0 & 0 \\
\hline GM3 & 0 & 0 & 0 & 0 \\
\hline \multicolumn{5}{|c|}{ Chondroitin sulphate $(2500)$} \\
\hline A & 0 & 0 & 20 & 15 \\
\hline B & 20 & 10 & 0 & +40 \\
\hline $\mathrm{C}$ & 20 & 10 & 0 & 0 \\
\hline Sialyl-lactose (500) & +10 & +10 & +10 & +40 \\
\hline \multicolumn{5}{|c|}{ In overlay medium during growth } \\
\hline \multicolumn{5}{|c|}{ Prostaglandins (1) } \\
\hline E2 & 0 & 0 & 0 & $+400^{*}$ \\
\hline $\mathrm{F} 2 \alpha$ & 0 & 0 & 0 & $+500^{*}$ \\
\hline \multicolumn{5}{|c|}{ Pre-treatment of virus for $1 \mathrm{~h}$ at $37^{\circ} \mathrm{C}$} \\
\hline Monolaurin (500) & 0 & 0 & & $100^{*}$ \\
\hline Vitamin A (100) & 0 & 0 & 0 & $100^{*}$ \\
\hline Human milk 1 & 10 & 0 & 0 & 15 \\
\hline Human milk 2 & $45^{\dagger+}$ & $60^{\dagger+}$ & 0 & 90 \\
\hline Human milk 3 & $70^{\dagger ま}$ & 0 & $70^{\dagger \dagger}$ & 30 \\
\hline
\end{tabular}


overlay medium. However, as monolaurin and vitamin A are toxic to cells at the concentrations used, the virus pre-treated with these factors was initially 10 -fold higher. This mixture was then diluted 10 -fold before the virus solution was absorbed to the cells.

The method of Isaacs et al. [21] was used to neutralise sIgA in human milk before testing its anti-rhinovirus activity. The detection of specific anti-rhinovirus sIgA by indirect immunofluorescence was performed as described previously [24].

\section{Results and discussion}

When the antimicrobial factors were tested for antiviral activity, none was found to have any significant effect on the growth of three strains of rhinoviruses (Table 1). The growth of the viruses was measured by the number of virus plaques produced. Furthermore, pre-treatment of these viruses with lactoferrin $1 \mathrm{mg} / \mathrm{ml}$ for $1 \mathrm{~h}$ at $37^{\circ} \mathrm{C}$ had no effect on virus growth. The only inhibition of virus growth occurred when the rhinoviruses were pre-treated with human milk (Table 1). However, inhibition of virus growth was variable, with the milk inhibiting only one or two of the rhinoviruses, but not all three. Inhibition of rhinovirus growth was accompanied by small surviving plaques $(1 \mathrm{~mm})$, which is indicative of the presence of specific virus neutralising antibody activity in the milk. This rhinovirus neutralising activity was removed by treatment of the milk samples for $1 \mathrm{~h}$ with anti-sIgA, before the milk was tested for antiviral activity to the rhinoviruses. The presence of specific sIgA to rhinoviruses was further confirmed by the use of indirect immunofluorescence with cells infected with the three different rhinoviruses. The milk samples did not inhibit all the rhinoviruses tested, suggesting that they did not possess any nonspecific anti-rhinovirus activity.

Breast milk protects against respiratory viruses, but these viruses do not infect infants from milk itself [1]. The present study investigated whether factors present in human milk could inhibit rhinovirus growth. The cellular absorption process of the non-enveloped rhinoviruses is known to involve the binding of the virus to either the intracellular adhesion molecule 1 (ICAM-1) receptor (rhinovirus major group) or the low-density lipoprotein (LDL) receptor (rhinovirus minor group, including rhinovirus 2). Milk compounds would either have to interfere with this adsorption process or inhibit the replication of the virus. However, soluble ICAM-1 (present in milk at $0.4 \mu \mathrm{g} / \mathrm{ml}$ ) [25] can not only inhibit the replication of major group rhinovirus 54, but can also disrupt the major group rhinoviruses 3 and 14. No compound tested, including lactoferrin, inhibited virus growth. There was no evidence that lactoferrin, which binds to the LDL receptor [17], could inhibit the growth of rhinovirus 2 or the two clinical rhinovirus isolates. Lactoferrin inhibits poliovirus absorption to cells and, in combination with zinc, can actually inhibit poliovirus (a similar virus to rhinoviruses) replication [17]. The present study found that only rhinovirus-specific sIgA neutralisation inhibited the binding of rhinoviruses. Immunoglobulin has been known to interfere with live poliovirus vaccines in infants for $>30$ years [26]. Both RSV and rhinoviruses have been implicated in involvement with otitis media. Exactly how breastfeeding protects against these viruses and this disease remains speculative. Protection may involve enhanced anti-infective or anti-inflammatory activity, or both, in breast-fed infants [2,3]. A possible mechanism as to how milk $\operatorname{sgA}$ protects infants against respiratory viruses has been proposed by Downham et al. [27]. They suggest that infants inhale milk during feeding (based on radiological studies) and regurgitate the milk through the nose. Once inhaled the $\operatorname{sIgA}$ persists for some time in a protective role.

When the factors were tested for antiviral activity against the milk-borne CMV isolate (Table 1), results similar to those observed previously with another clinical CMV isolate were found [4]. Lactoferrin, at the concentration found in human milk, and even at levels five-fold lower, strongly inhibited the growth of CMV; sialyl-lactose was found to slightly activate the virus, as did high levels of chondroitin sulphate $B$ (dermatan sulphate, $2.5 \mathrm{mg} / \mathrm{ml}$ ). The activation by chondroitin sulphate $\mathrm{B}$ was not found with the other clinical CMV isolate [4]. This was the only minor difference found between the two CMV strains. Pretreatment of either CMV strain with monolaurin and vitamin A completely inhibited growth. When the two prostaglandins, PGE2 and PGF $2 \alpha$, were added to the overlay medium, the growth of both CMV isolates increased considerably, by at least four-fold (Table 1). Not only did the prostaglandins increase the plaque numbers, the growth rate of the CMV was faster and the maximum number of plaques appeared 2 days earlier (at 5 days). Furthermore, the plaque size was at least double that of untreated CMV. The activation of the growth of both CMV isolates by the prostaglandins did not increase with concentrations $>1 \mu \mathrm{g} / \mathrm{ml}$ (Table $1)$, nor was there any increased growth with concentrations $<0.1 \mu \mathrm{g} / \mathrm{ml}$. An increase in growth of only $10 \%$ was observed at the $0.1 \mu \mathrm{g} / \mathrm{ml}$ concentration. The increased growth of $\mathrm{CMV}$ in the presence of these prostaglandins was reproducible throughout 10 separate experiments. Only one human milk sample tested had any significant inhibitory effect on the growth of milkborne CMV. Human milk inhibits CMV growth by either destroying the virus envelope due to the presence of potent antiviral lipids $[11,27]$, or by neutralising the virus with specific sIgA [29]. Nevertheless, CMV infects infants through milk $[1,15]$. The CMV milk isolate was found to have no particular resistance to any of the antiviral factors tested, compared with the other clinical CMV isolate. The presence of infectious $\mathrm{CMV}$ in milk has always been detected by virus 
isolation on HEL cells $[12,13]$. Moreover, isolation rates of infectious CMV are variable and $20-70 \%$ of mature milk samples can yield virus [15]. Recent studies usually include the simultaneous detection of the presence of CMV DNA in the milk samples with a specific PCR assay [30]. CMV DNA is usually detected in all milk samples from which CMV can be grown; however, up to $50 \%$ of the milk samples tested can be CMV DNA-positive without containing infectious virus [30]. The studies described here suggest that the addition of either prostaglandin present in human milk (i.e., PGE2 or PGF $2 \alpha$ ) to the virus growth medium at $1 \mu \mathrm{g} / \mathrm{ml}$ may allow enhanced isolation of infectious CMV from milk samples. Both these prostaglandins, when used at the concentrations indicated in this study, increased the growth and spread of other herpesviruses, HSV-1 and HSV-2 [31,32]. However, they inhibit the growth of parainfluenza 3 [4], a respiratory virus that infects infants. Not all prostaglandins enhanced CMV growth, as PGA1 inhibited growth. While the prostaglandins may be present in low concentrations in human milk [8], the total intake of prostaglandins by an infant fed $200 \mathrm{ml}$ of milk is considerable. Furthermore, if these prostaglandins are localised on particular cell receptors, they may be able to exert some influence on CMV infection. Certainly interleukin-8 can activate CMV replication in this manner [33].

This study confirmed the antiviral activity of lactoferrin against CMV strains [4]. Earlier studies showed that not only lactoferrin, but also ganglioside GM2 and chondroitin sulphate $\mathrm{B}$, inhibited the growth of RSV but lactoferrin was the only compound that inhibited RSV (and CMV) at concentrations less than that present in human milk $[4,8]$. Still other milk factors with potential antiviral activity remain to be determined, as demonstrated recently when human milk lysozyme was found to possess the ability to inhibit growth of HIV [34].

CMV (like HIV) is present in both human milk whey and milk cells [30] and it is not known precisely how enveloped viruses can survive these potent antiviral factors (as determined by in-vitro studies). CMV is not transmitted to infants exclusively through milk cells, unlike the enveloped T-lymphotrophic type 1 virus (HTLV-1). HTLV-1 may remain protected from the action of these factors by its cell association [1]. Nevertheless, transfer of HTLV-1 through milk to infants still requires at least 6 months of breast-feeding by their infected mothers, with only a quarter of the infants becoming infected [15]. Two-thirds of infants excreted CMV after only 3 weeks of breast-feeding on CMV-infected milk [29], which can contain up to $10^{3}$ tissue infective dose $50 \%$ of virus/ml $[1,29]$.

Despite the lack of confirmation of the precise mechanisms whereby infants are protected by human milk, which contains numerous antimicrobial agents [35], less respiratory and middle ear infections occur in breast-fed infants. Nevertheless, some viruses including CMV - are still capable of escaping such defences [35].

We thank Dr M. Kennett (Victorian Infectious Reference Laboratory, Melbourne) for supplying the rhinovirus isolates and Dr A. Watkins (Mercy Hospital for Women, Melbourne) for supplying human milk.

\section{References}

1. May JT. Microbial contaminants and antimicrobial properties of human milk. Microbiol Sci 1988; 5: 42-46.

2. Duncan B, Ey J, Holberg CJ, Wright AL, Martinez FD, Taussig LM. Exclusive breast-feeding for at least 4 months protects against otitis media. Pediatrics 1993; 91: 867-872.

3. Paradise JL, Elster BA, Tan L. Evidence in infants with cleft palate that breast milk protects against otitis media. Pediatrics 1994; 94: 853-860.

4. Portelli J, Gordon A, May JT. Effect of compounds with antibacterial activities in human milk on respiratory syncytial virus and cytomegalovirus in vitro. J Med Microbiol 1998; 47: 1015-1018.

5. Pitkäranta A, Virolainen A, Jero J, Arruda E, Hayden FG. Detection of rhinovirus, respiratory syncytial virus, and coronavirus infections in acute otitis media by reverse transcriptase polymerase chain reaction. Pediatrics 1998; 102: 291-295.

6. Sheng Sung B, Chonmaitree T, Broemeling LD et al. Association of rhinovirus infection with poor bacteriologic outcome of bacterial-viral otitis media. Clin Infect Dis 1993; 17: $38-42$.

7. Eikhatieb A, Hipskind G, Woerner D, Hayden FG. Middle ear abnormalities during natural rhinovirus colds in adults. $J$ Infect Dis 1993; 168: 618-621.

8. Grover M, Giouzeppos O, Schnagl RD, May JT. Effect of human milk prostaglandins and lactoferrin on respiratory syncytial virus and rotavirus. Acta Paediatr 1997; 86: 315-316.

9. Matthews THJ, Nair CDG, Lawrence MK, Tyrrell DAJ. Antiviral activity in milk of possible clinical importance. Lancet 1976; 2: 1387-1389.

10. Vochem M, Hamprecht K, John G, Speer CP. Transmission of cytomegalovirus to preterm infants through breast milk. Pediatr Infect Dis J 1998; 17: 53-58.

11. Welsh JK, Arsenakis M, Coelen RJ, May JT. Effect of antiviral lipids, heat, freezing on the activity of viruses in human milk. $J$ Infect Dis 1979; 140: 322-328.

12. Cheeseman SH, McGraw BR. Studies on cytomegalovirus in human milk. J Infect Dis 1983; 148: 615-616.

13. Dworsky M, Stagno S, Pass RF, Cassady G, Alford C. Persistence of cytomegalovirus in human milk after storage. $J$ Pediatr 1982; 101: 440-443.

14. Murph JR, Souza IE, Dawson JD et al. Epidemiology of congenital cytomegalovirus infection: maternal risk factors and molecular analysis of cytomegalovirus strains. Am J Epidemiol 1998; 147: 940-947.

15. May JT. Antimicrobial factors and microbial contaminants in human milk: recent studies. J Paediatr Child Health 1994; 30: $470-475$.

16. Superti F, Ammendolia MG, Valenti P, Seganti L. Antirotaviral activity of milk proteins: lactoferrin prevents rotavirus infection in the enterocyte-like cell line HT-29. Med Microbiol Immunol 1997; 186: 83-91.

17. Marchetti M, Superti F, Ammendolia MG, Rossi P, Valenti P, Seganti L. Inhibition of poliovirus type 1 infection by iron-, manganese- and zinc-saturated lactoferrin. Med Microbiol Immunol 1999; 187: 199-204.

18. Auperin DD, Reinhardt A, Sands JA, Snipes W, Taylor WD. Characterisation of virucidal activity of retinoids. In: Current chemotherapy and infectious diseases. Proceedings of the 11th ICC and 19th ICACC. Washington, American Society Microbiology. 1980: 1368-1370.

19. Ikeda M, Sugiyama K, Tanaka $\mathrm{T}$ et al. Lactoferrin markedly inhibits hepatitis $\mathrm{C}$ virus infection in cultured human hepatocytes. Biochem Biophys Res Commun 1998; 245: 549-553. 
20. Van de Perre P. Transmission of human immmunodeficiency virus type 1 through breast-feeding: How can it be prevented? J Infect Dis 1999; 179 Suppl 3: S405-S407.

21. Isaacs $\mathrm{CE}$, Thormar $\mathrm{H}$, Pessolano $\mathrm{T}$. Membrane-disruptive effect of human milk: inactivation of enveloped viruses. J Infect Dis 1986; 154: 966-971.

22. Orloff SL, Wallingford JC, McDougal JS. Inactivation of human immunodeficiency virus type 1 in human milk: effects of intrinsic factors in human milk and of pasteurization. J Hum Lact 1993; 9: 13-17.

23. Conley AJ, Kabara JJ. Antimicrobial action of esters of polyhydric alcohols. Antimicrob Agents Chemother 1973; 4: 501-506.

24. Welsh JK, Skurrie IJ, May JT. Use of Semliki Forest virus to identify lipid-mediated antiviral activity and anti-alphavirus immunoglobulin A in human milk. Infect Immun 1978; 19: 395-401.

25. Rudloff S, Niehues T, Rutsch M, Kunz C, Schroten H. Inflammation markers and cytokines in breast milk of atopic and nonatopic women. Allergy 1999; 54: 206-211.

26. Plotkin SA, Katz M, Brown RE, Pagano JS. Oral poliovirus vaccination in newborn African infants. The inhibitory effect of breast feeding. Am J Dis Child 1966; 111: 27-30.

27. Downham MAPS, Scott R, Sims DG, Webb JKG, Gardner PS. Breast-feeding protects against respiratory syncytial virus infections. BMJ 1976; 2: 274-276.

28. Heirholzer JC, Kabara JJ. In vitro effects of monolaurin compounds on enveloped RNA and DNA viruses. $J$ Food Safety 1982; 4: 1-12.

29. Alford C. Breast milk transmission of cytomegalovirus (CMV) infection. In: Mestecky $J$ (ed) Infection of milk and the neonate. New York, Plenum Press. 1991: 293-299.

30. Asanuma H, Numazaki K, Nagata N, Hostsubo T, Horino $K$, Chiba S. Role of milk whey in the transmission of human cytomegalovirus infection by breast milk. Microbiol Immunol 1996; 40: 201-204.

31. Harbour DA, Blyth WA, Hill TJ. Prostaglandins enhance spread of herpes simplex virus in cell cultures. J Gen Virol 1978; 41: 87-95.

32. Baker DA, Thomas J, Epstein J, Possilico D, Stone ML. The effect of prostaglandins on the multiplication and cell-to-cell spread of herpes simplex virus type2 in vitro. Am $J$ Obstet Gynecol 1982; 144: 346-349.

33. Murayama T. [Interrelationship between human cytomegalovirus infection and chemokine.] Nippon Rinsho 1998; 56: $69-74$.

34. Lee-Huang S, Huang PL, Sun Y et al. Lysozyme and RNases as anti-HIV components in $\beta$-core preparations of human chorionic gonadotrophin. Proc Natl Acad Sci USA 1999; 96: 2678-2681.

35. May JT. Human milk - Tables of the antimicrobial factors and microbial contaminants relevant to human milk banking (with continued updating). http://www.latrobe.edu.au/www/microbio/ milk.html 